\title{
Osmolality control by inhalation or micro-infusions?
}

\author{
G. Ciofani ${ }^{1}$, A. Landi ${ }^{2}$, D. Mazzei ${ }^{1} \&$ A. Mazzoldi ${ }^{1}$ \\ ${ }^{1}$ Interdipartmental Research Center "E.Piaggio", \\ Faculty of Engineering, University of Pisa, Pisa, Italy \\ ${ }^{2}$ Department of Electrical Systems and Automation, \\ Faculty of Engineering, University of Pisa, Pisa, Italy
}

\section{Abstract}

A model of osmolarity is proposed in this paper. This model represents a typical example of embedded physiological feedback control in physiology. Extensive simulation tests with a compartmental approach (using the specific software SAAM II) have been performed, showing that the model agrees with the findings published in the literature of endocrine physiology and with medical practice. As a relevant example of application of the models, the diabetes insipidus pathology was considered. In the case of central insipidus diabetes, it is possible to predict effects of a therapy, giving out synthetic ADH (where ADH is the antidiuretic hormone, the vasopressine) for restoring homeostatic conditions.

Two kinds of therapy were considered: supply by inhalation or by microinfusion.

In the first case, we evaluated the effect of inhalation using a two compartmental model to describe the effect of commercial drug (minirin, that means desmopressine acetate), and compared results with data existing in the literature.

In the second case, the aim was to have a helping tool in the study and development of micro-infusors with sensors and controllers embedded so as to be able to release a controlled drug quantity, accorded to the patient and optimized for avoiding hyper- or ipo-concentrations of plasma ADH hormone.

In this case, we used a mono-compartmental model, considering that the drug is infused directly in the plasma; results are again compared with data existing in the literature and with experimental data.

Keywords: compartmental model, osmolality, ADH, total body fluid volume, central and nephrogenic diabetes insipidus, synthetic ADH, minirin, desmopressine acetate, inhalation, infusors. 


\section{Introduction}

The term "homeostasis" [1] is used in physiology to indicate the maintaining of constant conditions inside an organism.

Several physiology studies are dedicated to understand how the various organs contribute to realize this homeostasis and therefore how this control systems of our body work.

The human body has, in fact, thousand of system controls. Some of these work inside cells to turn intracellular functions, other work inside organs to control their functions and their action in combination with other organs.

In this document, we used a compartmental approach (using the specific software SAAM II) to model one of the basic systems to maintain the physiological homeostasis: the regulation of osmolality of physical liquids, realized by endocrine systems through the kidneys.

The kidneys are responsible for regulating the volume and concentration of body fluids, by selectively filtering and reabsorbing materials from the blood [2]. This system is one of the most relevant examples of embedded physiological feedback control in physiological homeostasis: it is a subject typical of humane endocrine system and like every model correlated with endocrinology it involves several effects acting concurrently on different organs. Therefore it constitutes a very complex model and requires a careful attention for achieving an effective simplification of the model itself. Furthermore maximum effort was due to linearize as much as possible the nonlinear functions involving different variables of interest.

As many engineering models applied to complex systems, a major problem was due to the limited availability of experimental data collection useful for defining exact parameters, in terms of physiological-physics insights of the system: our efforts have been devoted to obtain modelling solutions similar to steady-state physiological data available in medical literature, regarding hormonal concentrations, total body fluid volume and osmolality, along with time constants matching with clinical observations. To authors' knowledge, the subject at hand is rarely considered from engineers: a unique interesting model of osmolality was dated at 1972 [3]. It was a complex and well-detailed model, based on the movements of body fluid between the intravascular, interstitial and intracellular compartments and to their reciprocal fluid interchanges.

The model proposed in this paper is simpler and considers a "whole-body" analysis, in order to select as output variable only the ones comparable with medical typical available data (e.g., acquired from a clinical dehydration test typical for checking diabetes insipidus).

Furthermore, dynamic non-linearities are linearized, due to the consideration that only small variations with respect to homeostasis are allowed in practice, i.e., the model belongs to the class of small signal models, well-known, e.g., in the field of power electronics. Obviously, the problem remains complex, so we made also some simplifications.

The model has been developed with an analytical approach, based on differential equations and compartmental approach [4]. 
We considered also pathological case, and a possible recovering with drugs, through a pharmacokinetics approach.

In fact, at the end, we considered the case of a patient affect by central diabetes insipidus. It is supposed subjected to a "thirst test", and we evaluated results of the test, considering two different pharmacological approaches: traditional therapy (minirin, i.e. desmopressine acetate, inhalation) and a hypothetic microinfusor with sensors and controllers embedded able to release a controlled drug quantity.

\section{Compartmental model to maintain the body homeostasis}

We consider now the state space model in a neighbourhood of a homeostasis, corresponding to normal mean conditions of healthy and adult people: this starting hypothesis leads to linear models with thresholding nonlinearities. State variables for the osmolality model are: the electrolytes amount $\left(q_{1}\right)$, the ADH amount (where $\mathrm{ADH}$ is the antidiuretic hormone, the vasopressine) $\left(\mathrm{q}_{2}\right)$ and the total body fluid volume $\left(\mathrm{q}_{3}\right)$.

The osmolality is obtained by simple ratio $\mathrm{s}_{1}=\mathrm{q}_{1} / \mathrm{q}_{3}$.

ADH release is a typical example of feedback control (Fig.1).

As soon as the osmolality of the blood and body fluids are reduced, the receptors in the hypothalamus are no longer stimulated and the level of ADH stimulation is reduced, which signals to the kidneys to start excreting more water in the urine production, until the blood osmolality increases enough for the cycle to be started again [5].

Since body fluid osmolality is in equilibrium with plasma osmolality, we consider two input signals in the model.

The first one $\left(\mathrm{B}_{1}\right)$ is the quantity (in $[(\mathrm{oSmol} / \mathrm{kg})(\mathrm{lt} / \mathrm{min})]$ of active solute of a salt solution injected via intravenous (IV) infusion, the second one $\left(B_{2}\right)$ is the quantity (in [lt $/ \mathrm{min}]$ ) of water injected via IV infusion.

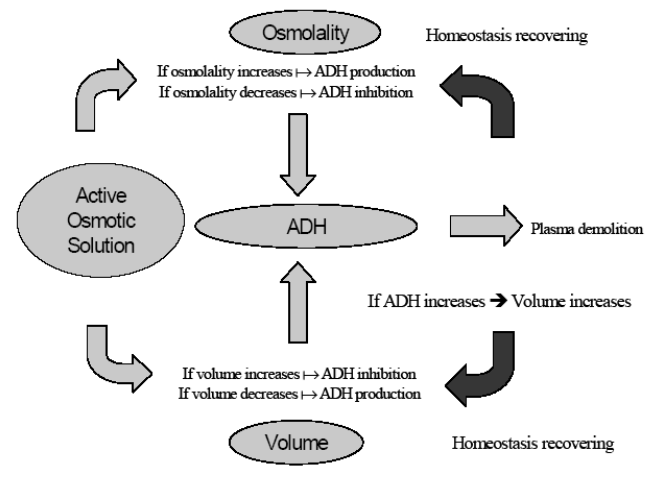

Figure 1: ADH feed back action on osmolality and body fluid volume. 
At the end of the infusion, the osmolality $[\mathrm{oSmol} / \mathrm{kg}]$ of the injected solution is defined as the ratio between the total amount of electrolyte infused and the total amount of water infused, $\mathrm{B}_{1} / \mathrm{B}_{2}$.

A dose or infusion $\mathrm{B}_{3}$ of synthetic $\mathrm{ADH}$ will be also considered.

These considerations lead to the above mathematical model (Figure 1).

With this approach, the amount of fluid total volume is explicitly and directly connected to the electrolytes concentration, and this is posed in relation to the ADH effect.

The compartmental equations are:

$$
\begin{array}{ll}
\dot{q}_{1}=0 ; & q_{1}(0)=I_{1} \\
\dot{q}_{2}=-k_{02} q_{2} & q_{2}(0)=I_{2} \\
\dot{q}_{3}=-k_{03} q_{3} & q_{3}(0)=I_{3}
\end{array}
$$

The external input to compartment 1 is composed by two parts: the initial electrolyte dose, $\mathrm{I}_{1}\left(\mathrm{I}_{1}=\mathrm{C}_{1} * \mathrm{C}_{3},[(285 \mathrm{mOsm} / \mathrm{Kg}) *(40 \mathrm{lt})]\right)$; the second one is a constant infusion of electrolytes $\mathrm{B}_{1}$, connected to the specific experiment..

Likewise, the external input to compartment 2 is composed by some parts.

The first one is the initial ADH dose, $I_{2}\left(I_{2}=C_{2} V 2\right.$, [ng], where $V_{2}$ is the volume [lt] distribution of $\mathrm{ADH})$.

The second one is the input regulated by rate influence $\mathrm{RI}_{2}$ of amount of electrolytes and of total body fluid volume:

$$
\mathrm{RI}_{2}=\mathrm{a}_{4}\left(\mathrm{q}_{1} / \mathrm{q}_{3}-\mathrm{C}_{1}\right) * \mathrm{~F}\left(\mathrm{q}_{1} / \mathrm{q}_{3}\right)
$$

where $\mathrm{F}\left(\mathrm{q}_{1} / \mathrm{q}_{3}\right)$ is a special function of $\mathrm{q} 1 / \mathrm{q} 3$, and it is described below).

This second term shows an increase of $\mathrm{ADH}$ amount if the osmolality increases over the homeostatic value, $\left.\mathrm{C}_{1}[285 \mathrm{mOsm} / \mathrm{kg})(40 \mathrm{lt})\right]$.

Because this term works as a threshold function, we introduced the function $\mathrm{F}(\mathrm{x})=\mathrm{F}\left(\mathrm{q}_{1} / \mathrm{q}_{3}\right)$, which has value 1 , if the $\mathrm{x}=\mathrm{q} 1 / \mathrm{q} 3$ is over the threshold $\mathrm{C}_{1}$, otherwise it is equal to 0 (see Figure 2).

This function $\mathrm{F}(\mathrm{x})$, is defined as:

$$
F(x)=\left[\frac{1}{\pi} \arctan \left(100 \cdot \frac{x-285}{A}\right)\right]+0.5
$$

where $\mathrm{A}=1[\mathrm{mOsm} / \mathrm{kg}]$.

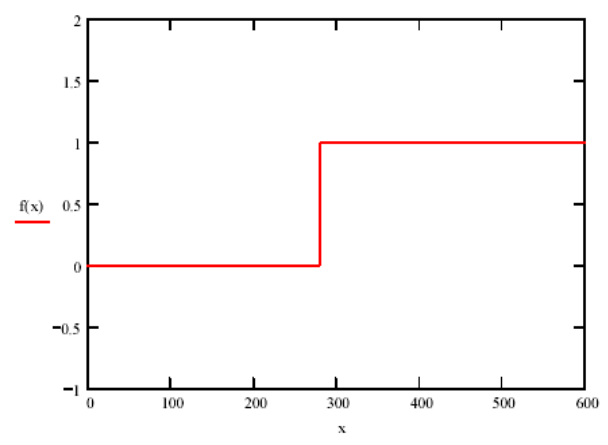

Figure 2: $\quad$ Graphic of $\mathrm{F}(\mathrm{x})(\mathrm{x}$ is in $[\mathrm{mOsm} / \mathrm{Kg}])$. 
A constant $\mathrm{ADH}$ infusion $\mathrm{B}_{2}$ connected to the specific experiment can be also inserted.

The $\mathrm{ADH}$ plasmatic demolition is connected to $\mathrm{k}_{02}$ parameter, where:

$$
\mathrm{k}_{02}=\mathrm{a}_{9}\left(\mathrm{q}_{2}-\mathrm{C}_{2} \mathrm{~V}_{2}\right) / \mathrm{q}_{2}
$$

In the last equation, the external input is constituted by three elements:

-the total body fluid volume physiological value, $\mathrm{I}_{3}\left(\mathrm{I}_{3}=\mathrm{C}_{3}\right.$, [40 lt $]$ ) -the constant water infusion $\mathrm{B}_{3}$ connected to the specific experiment -the rate influence $\mathrm{RI}_{3}$ of $\mathrm{ADH}$, which represents the effect of amount of amount of $\mathrm{ADH}$ on the total body fluid volume retention:

$$
\mathrm{RI}_{3}=\mathrm{a}_{7}\left(\mathrm{q}_{2}-\mathrm{C}_{2} \mathrm{~V}_{2}\right)
$$

Then, $\mathrm{k}_{03}$ parameter evaluates the effect of the osmolality level on total body volume fluid, with the following formula:

$$
\mathrm{k}_{03}=\left[\mathrm{a}_{8}\left(\mathrm{q}_{3}-\mathrm{C}_{3}\right) / \mathrm{q}_{3}\right] \mathrm{F}\left(-\left(\mathrm{q}_{1} / \mathrm{q}_{3}\right)\right) \text {. }
$$

Here $F(x)=F(-(q 1 / q 3))$ is defined such as the previous function,

$$
F(x)=\left[\frac{1}{\pi} \arctan \left(100 \cdot \frac{285-x}{A}\right)\right]+0.5
$$

In this case, $\mathrm{F}(\mathrm{x})$ is 1 , for $\mathrm{x}$ below the threshold $\mathrm{C}_{1}=285[\mathrm{mOsm} / \mathrm{kg}]$, otherwise it is equal to 0 .

Therefore $\mathrm{F}$ shows a decreasing of body fluid volume, if the osmolality $\mathrm{x}=$ $\mathrm{q} 1 / \mathrm{q} 3$ is under the physiological values.

With these considerations, the three equations can be so rewritten:

$$
\begin{array}{ll}
\dot{q}_{1}=B_{1} & q_{1}(0)=I_{1}=C_{1} \cdot C_{3} \\
\dot{q}_{2}=B_{2}+a_{4}\left(\frac{q_{1}}{q_{3}}-C_{1}\right) F\left(\frac{q_{1}}{q_{3}}\right)-a_{9}\left(q_{2}-C_{2} V_{2}\right) & q_{2}(0)=I_{2}=C_{2} \cdot V_{2} \\
\dot{q}_{3}=B_{3}+a_{7}\left(q_{2}-C_{2} V_{2}\right)-a_{8}\left(q_{3}-c_{3}\right) F\left(-\frac{q_{1}}{q_{3}}\right) & q_{3}(0)=I_{3}=C_{3}
\end{array}
$$

where $B_{i}$ are the infusions on compartment " $i$ ", connected to the specific experiments. $\mathrm{I}_{\mathrm{i}}$.

If doses are administrated, they are directly added to the physiological values

The compartmental schema is as in Figure 3. Here $\mathrm{s}_{1}=\mathrm{q}_{1} / \mathrm{q}_{3}, \mathrm{~s}_{2}=\mathrm{q}_{2} / \mathrm{V}_{2}$ and $\mathrm{ex}_{\mathrm{i}}$ represent initial conditions and external inputs. 


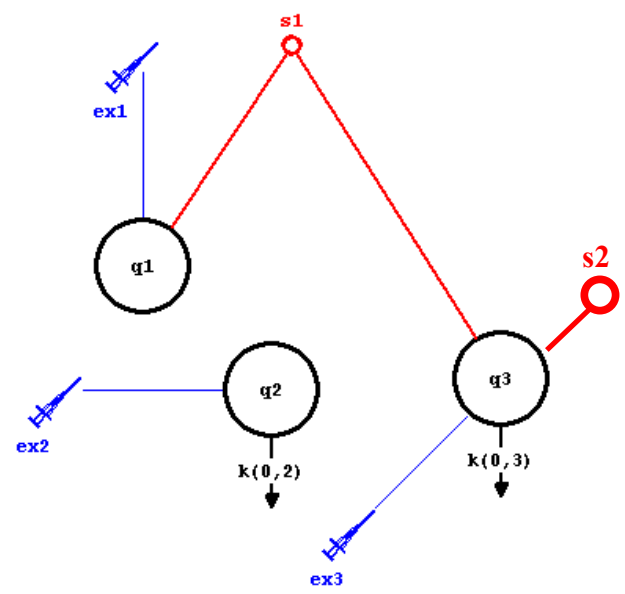

Figure 3: Compartmental scheme of the model.

\section{Simulations in different conditions}

Different tests have been performed in order to verify the validity of the model.

We considered the following cases:

-the adding of an hyper-osmotic solution (concentration 4 times higher than the physiological value $\mathrm{C}_{1}$ )

-the adding of an ipo-osmotic solution (concentration 4 times lower than the physiological value $\mathrm{C}_{1}$ )

-the adding of an iso-osmotic solution (concentration equal to $\mathrm{C}_{1}$ ).

The solutions are supposed to be added for an amount of $0.5 \mathrm{lt}$ in about $30 \mathrm{~min}$.

The following figures (Figure 4, Figure 5 and Figure 6) show the osmolality (on the left, $[\mathrm{mOsm} / \mathrm{kg}]$ ) and the $\mathrm{ADH}$ concentration (on the right, [ng/lt]), respectively, during hyper-, ipo- and iso-osmotic tests.
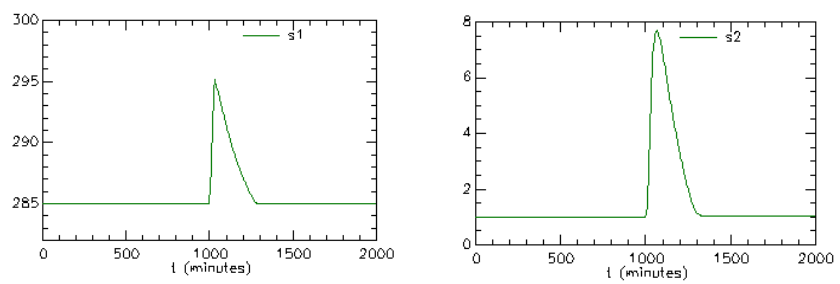

Figure 4: Osmolality $s_{1}[\mathrm{mOsm} / \mathrm{kg}]$ and ADH concentration $\mathrm{s}_{2}[\mathrm{ng} / \mathrm{lt}]$ vs. time, during hyper-osmotic test. 

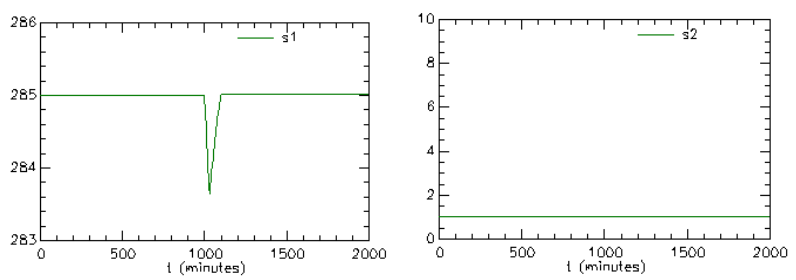

Figure 5: Osmolality $s_{1}[\mathrm{mOsm} / \mathrm{kg}]$ and ADH concentration $\mathrm{s}_{2}[\mathrm{ng} / \mathrm{lt}]$ vs. time, during ipo-osmotic test.
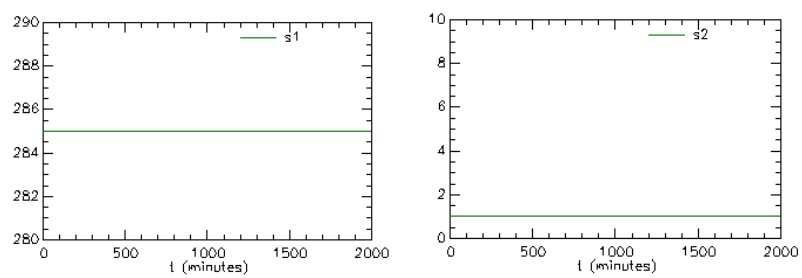

Figure 6: Osmolality $\left.\mathrm{s}_{1}[\mathrm{mOsm} / \mathrm{kg})\right]$ and ADH concentration $\mathrm{s}_{2}[\mathrm{ng} / \mathrm{lt}]$ vs. time, during iso-osmotic test.

In all the cases, the calculated behaviours are coherent with physiological ones.

\section{Simulation of a pathological condition: diabetes insipidus}

The concentration of urine (also called osmolality or specific gravity) may be important in diagnosing abnormal kidney function.

As a relevant example of application of the proposed model, we consider the diabetes insipidus case.

This pathology is strictly correlated with a failure in the embedded control loop of osmolality.

It can be classified into two main categories.

The first category is central diabetes insipidus case: it usually results from the decreased production of $\mathrm{ADH}$, the hormone regulating the amount of total body fluid volume. It causes excessive production of very dilute urine (polydipsia) with a severe increasing of osmolality, unless the patient does not assume a great deal of water, to compensate for the fluid lost in urine.

The second one is nephrogenic diabetes insipidus: it is a disorder characterized by the passage of large volumes of urine due to a defect of the kidney tubules. In this pathology $\mathrm{ADH}$ is normally produced, but the kidney defect usually produces a partial or complete failure of receptors located on or within the kidney tubules to respond to ADH. Also in this pathology, patients are unable to control osmolality and the effects are similar to the ones previously described. 
With the model for the osmolality (described above), we have simulated both pathologies [6]. Here we consider the case of central insipidus diabetes, the most interesting for an application of the model proposed, since in this pathology it is possible a therapy giving out synthetic $\mathrm{ADH}$ (minirin, i.e. desmopressine acetate) for restoring homeostatic conditions.

The SAAM II implementation of the model in case of pathologic conditions is simple: parameters involved in the $\mathrm{ADH}$ production are set to zero and a pharmacologic approach is considered, making us of an external input representing the administration of synthetic ADH (OS dose or IV infusion, typically $20 \mathrm{mg} / \mathrm{die}$ or $0.5^{*} \mathrm{~V}_{2}$ [ng/min], respectively). This input is active if the osmolality exceeds the physiological value $\mathrm{C}_{1}$.

The time delay characteristic of ADH synthesis is eliminated making in the hypothesis of a direct IV infusion of synthetic ADH.

As experiments, we consider the daily water deprivation clinical test.

With this test, medical doctors are able to detect the pathology type.

This test consists in water deprivation for 12 hours and in measurements of plasmatic osmolality and of urine amount production.

If there is a high increase of osmolality, the patient is affect by diabetes insipidus.

If osmolality decreases after administration of synthetic ADH (desmopressine acetate), the diabetes insipidus is of central type.

The graphics of osmolality [mOsm/kg] and ADH concentration ([ng/lt]) for a patient affected by diabetes insipidus of central types during daily water deprivation clinical test (without administration of drug) are reported in Figure 7 (the patient had a water loss estimated in 2.5 lt of water in 12 hours; such loss was the input of the osmolality model).

Obviously the graphics of $\mathrm{ADH}$ concentration is flat and equal to 0 , considering that there is not natural production of $\mathrm{ADH}$, and there is not external introduction of synthetic ADH.

The little squares show experimental data and there is a good fitting between experimental data and model prediction.
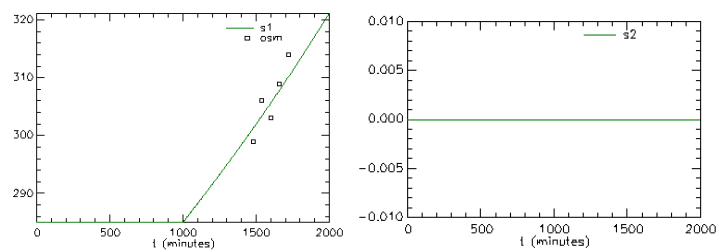

Figure 7: Osmolarity $\left(\mathrm{s}_{1}\right)[\mathrm{mOsm} / \mathrm{kg}]$ and ADH concentration $\left(\mathrm{s}_{2}\right)(\mathrm{ng} / \mathrm{lt}) \mathrm{vs}$. time, during water deprivation clinical test, for a patient affected by diabetes insipidus of central type, without external administration of synthetic $\mathrm{ADH}$. (the little square on the left graphics are experimental data of osmolality). 
The following simulation was developed to show the effect of a therapy, with the administration of minirin (i.e. desmopressine acetate), by inhalation. Generally, a dose of spray of $20 \mathrm{mg} /$ die in the nostrils is the used value.

Starting from indications reported in literature, we developed a bicompartmental model of desmopressine acetate: the first compartment represents the nasal area (with high leakage of substance), the second one represents the plasma, where the synthetic and natural $\mathrm{ADH}$ is also decomposed.

In particular, from the data reported in literature regarding the desmopressine acetate concentration in the plasma after inhalation of a dose $D_{2}$ of $20 \mathrm{mg}$ of products [7], we calculated the kinetic constant for the model we developed and solved it.

This second model substitutes the part dedicated to $q_{2}$ in the model initially reported, so the new full model is as reported in Figure 8.
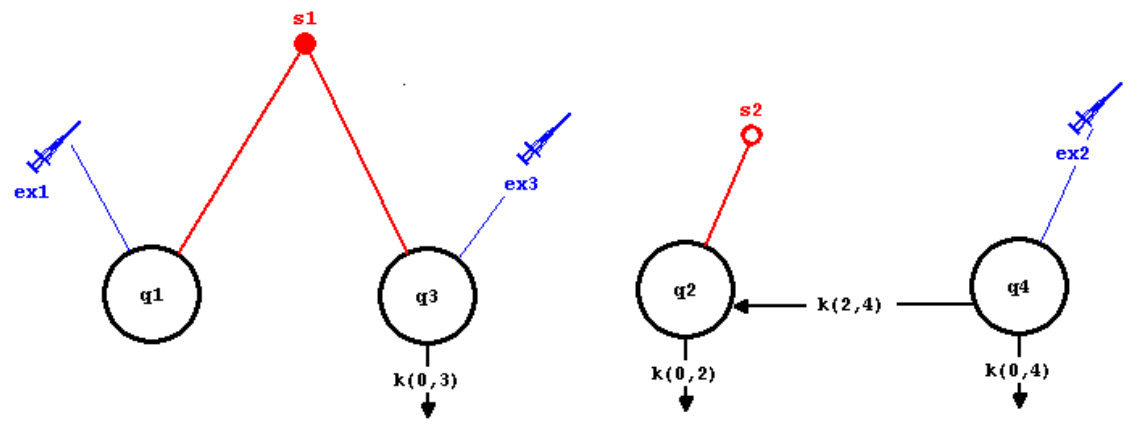

Figure 8: Compartmental scheme of the model, in the case of patient affect by diabetes insipidus of central type, with external administration of synthetic ADH.

$\mathrm{Ex}_{2}$ is the dose $\mathrm{D}_{2}$ of $20 \mathrm{mg}$ of synthetic $\mathrm{ADH}$ given to the patient, $\mathrm{s}_{2}$ is the plasmatic concentration of desmopressine acetate.
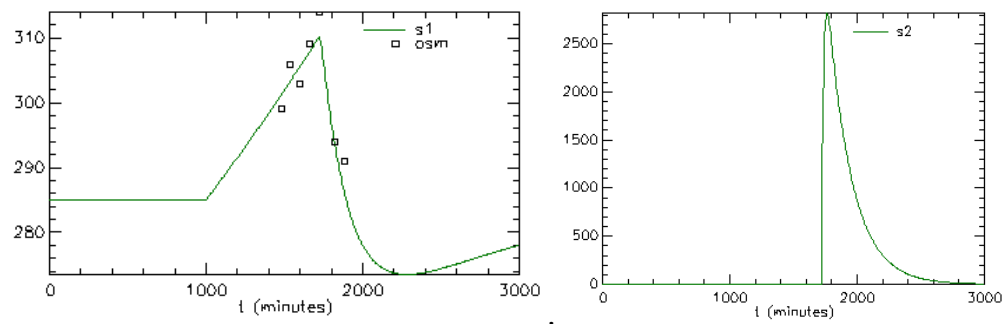

Figure 9: Osmolality $\left(\mathrm{s}_{1}\right)[\mathrm{mOsm} / \mathrm{kg}]$ and $\mathrm{ADH}$ concentration $\left(\mathrm{s}_{2}\right)$ [ng/lt] vs. time, during water deprivation clinical test, for a patient affected by diabetes insipidus of central type, with external administration of synthetic ADH with spray (the little square on the left graphics are experimental data of osmolality). 
Figure 9 shows results of simulation of osmolality (on the left) and of synthetic $\mathrm{ADH}$ (on the right) vs. time for a patient affected by central diabetes insipidus, during synthetic $\mathrm{ADH}$ administration.

The little squares show experimental data and again there is a good fitting between experimental data and model prediction.

We considered then a similar experiment, where a micro-infusor with sensors and controllers embedded able to release a controlled drug quantity [8], accorded to the patient and optimized for avoiding hyper or ipo-concentrations of plasma ADH hormone.

In this case we used a mono-compartmental model (which is the plasma), considering that the drug is infused directly in the plasma; results are again compared with data existing in literature and with experimental data.

The flues of the drugs can be calculated ad hoc, to avoid over or under medication.

The scheme is analogues to that of Figure 3 (see before), but now $\mathrm{ex}_{2}$ is of exogenous nature and not endogenous (ADH is administrated by drug and not produced inside the body).

How it is possible to see in Figure 10, calculated osmolality values are very lower respect values of literature previously already described; then shape of plasmatic curve of synthetic ADH is more smooth.

All that gives idea of a more acceptable use of the drugs.
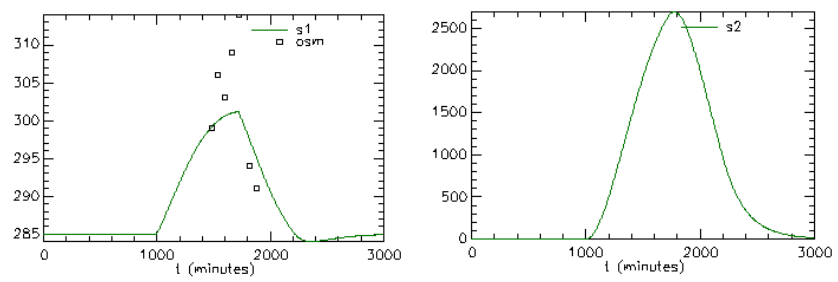

Figure 10: Osmolaity $\left.\left(\mathrm{s}_{1}\right)[\mathrm{mOsm} / \mathrm{kg})\right]$ and ADH concentration $\left(\mathrm{s}_{2}\right)[\mathrm{ng} / \mathrm{lt}] \mathrm{vs}$. time, during water deprivation clinical test, for a patient affected by diabetes insipidus of central type, with external administration of synthetic ADH with micro-infusor (the little square on the left graphics are experimental data of osmolality, obtained by spray use).

\section{Conclusions and future developments}

The results obtained in simulation tests offer coherent values with the medical practice, in hyper-, ipo-, and iso-osmotic condition.

The simulation models may be a helping tool in the turn of spray use and in the study and development of micro-infusors with sensors and controllers embedded able to release a controlled drug quantity, accorded to the patient and optimized for avoiding hyper- or ipo-concentrations of plasma ADH hormone.

Future goals of the research are devoted to a more strict validation of coefficients after an accurate analysis of clinical data. For improving the model accuracy, studies are in progress for adding different factors that interacts with 
the system, e.g., the rate of glomerulare filtration or the control of excretion of sodium and potassium.

\section{Appendix}

$\mathrm{q}_{1}$ : amount of electrolytes $[(\mathrm{mOsm} / \mathrm{kg})(40 \mathrm{lt})]$ (normal value is around 285 $[(\mathrm{mOsm} / \mathrm{kg})(40 \mathrm{lt})])$.

$\mathrm{q}_{2}$ : amount of $\mathrm{ADH}[\mathrm{ng}]$ (normal value is around $\left(\mathrm{C}_{2} * \mathrm{~V}_{2}\right)[\mathrm{ng}]=[\mathrm{pmol}]$ ).

q3: amount of the total body fluid volume [1t] (normal value is around 40 [1t]).

$\mathrm{C}_{1}$ : homeostatic oemolality $(285[\mathrm{mOsm} / \mathrm{kg}])$.

$\mathrm{C}_{2}$ : homeostatic concentration of $\left.\mathrm{ADH}(1[\mathrm{ng} / \mathrm{lt}])=1[\mathrm{pmol} / \mathrm{lt}]\right)$.

$\mathrm{C}_{3}$ : homeostatic total volume of body fluids (40 [1t]).

$\mathrm{k}_{02}$ : it is connected to effect of ADH plasmatic demolition [1/min].

$\mathrm{k}_{03}$ : it is connected to effect of osmolality on total body volume fluid[1/min].

$\mathrm{RI}_{2}$ : rate influence of amount of electrolytes and of total body fluid volume on $\mathrm{ADH}$ input [ng/min].

$\mathrm{RI}_{3}$ : rate influence of amount of $\mathrm{ADH}$ on the total body fluid volume retention $[1 \mathrm{t} / \mathrm{min}]$.

$\mathrm{a}_{4}$ : it is connected to effects of increasing of osmolality on ADH production $\left(\mathrm{a}_{4}=0.04[\mathrm{lt} / \mathrm{min}]\right)$.

$a_{7}$ : it is connected to ADH effect on the total body fluid (a7 $\left.=0.001[1 / \mathrm{min}]\right)$.

$\mathrm{a}_{8}$ : it is connected to osmolality effect on the total body fluid $\left(\mathrm{a}_{8}=0.01[1 / \mathrm{min}]\right)$.

$\mathrm{a}_{9}$ : it is connected to ADH plasmatic demolition $\left(\mathrm{a}_{9}=0.05[1 / \mathrm{min}]\right)$.

$\mathrm{V}_{2}$ : volume of distribution of $\mathrm{ADH}$ [1t] (its value is depending on the structure of patient and can be determined by dose test and measurement of concentration).

$\mathrm{s}_{1}$ : osmolality [mOsm $\left./ \mathrm{kg}\right]$ (normal value is around: $285[\mathrm{mOsm} / \mathrm{kg}]$ ).

$\mathrm{s}_{2}$ : ADH concentration [ng/lt] (normal value is around $1[\mathrm{ng} / \mathrm{lt}]=1[\mathrm{pmol} / \mathrm{lt}]$ ).

$\mathrm{ex}_{\mathrm{i}}$ : they represent initial conditions and external inputs.

$\mathrm{B}_{1}$ : electrolytes infusion in hyper-osmotic case $\left(\mathrm{B}_{1}=4 *(285 * 40 * 0.5) / 30\right.$ $[(\mathrm{mOsm} / \mathrm{kg})(\mathrm{lt} / \mathrm{min})])$.

electrolytes infusion in ipo-osmotic case $\left(\mathrm{B}_{1}=0.25 *(285 * 40 \quad 0.5) / 30\right.$ $[(\mathrm{mOsm} / \mathrm{kg})(\mathrm{lt} / \mathrm{min})])$.

electrolytes infusion in iso-osmotic case $\left(\mathrm{B}_{1}=1 *(285 * 40 * 0.5) / 30\right.$ $[(\mathrm{mOsm} / \mathrm{kg})(\mathrm{lt} / \mathrm{min})])$.

$\mathrm{B}_{2}$ : endogenous $\mathrm{ADH}$ infusion in hyper-osmotic case $\left(\mathrm{B}_{2}=0[\mathrm{ng} / \mathrm{min}]\right)$.

endogenous $\mathrm{ADH}$ infusion in ipo-osmotic case $\left(\mathrm{B}_{2}=0[\mathrm{ng} / \mathrm{min}]\right)$.

endogenous $\mathrm{ADH}$ infusion in iso-osmotic case $\left(\mathrm{B}_{2}=0[\mathrm{ng} / \mathrm{min}]\right)$.

exogenous synthetic $\mathrm{ADH}$ infusion during water deprivation clinical test

for central diabetes insipidus $\left(\mathrm{B}_{2}[\mathrm{ng} / \mathrm{min}]\right.$ is considered proportional to $\mathrm{s}_{1}$, if $\left.\mathrm{s}_{1}>285[\mathrm{mOsm} / \mathrm{kg}]\right)$.

$\mathrm{B}_{3}$ : water infusion in hyper-osmotic case $\left(\mathrm{B}_{3}=0.5 / 30[\mathrm{lt} / \mathrm{min}]\right.$. water infusion in ipo-osmotic case $\left(\mathrm{B}_{3}=0.5 / 30[\mathrm{lt} / \mathrm{min}]\right.$. water infusion in iso-osmotic case $\left(\mathrm{B}_{3}=0.5 / 30[\mathrm{lt} / \mathrm{min}]\right.$.

D2: exogenus synthetic $\mathrm{ADH}$ dose during water deprivation clinical test for central diabetes insipidus $\left(\mathrm{D}_{2}=20[\mathrm{mg}]\right)$. 


\section{Acknowledgments}

The authors thank Dr. M. Gaspari and Dr. L. Morselli of the Department of Endocrinology and Metabolism, University of Pisa, for their clinical supervision and their helpful comments on the presented model.

\section{References}

[1] Cannon W, The Wisdom of the Body, Norton, New York, 1939.

[2] Walsh P.C. et al., Urologia di Campbell; VII edizione, Verducci Editore, 1999.

[3] Merletti R., Weed H.R., Nonlinear Model of body Fluid and Osmolality Control System, in Proceedings of the 5th IFAC World Congress, Paris, pp. 25.1-25.7, 1972.

[4] Jacquez J.A., Compartmental analysis in biology and medicine, Biomedware, 1996.

[5] Guyton A.C., Trattato di fisiologia medica; IV edition, PICCIN, 1995.

[6] Ciofani G., Landi A., Mazzei D., Mazzoldi A., Physiological cybernetics: model of osmolality and volemia, the European Control Conference (ECC) and the IEEE Conference on Decision and Control (CDC), Siviglia, Spain, 2005

[7] Joukhadar Christian, Scehenk Barbara, Kaehler Stefan T., Kollenz Christian J., Bauer Peter, Muller Markus, Eichle Hans-Georg, A replicate study design for testing bioequivalence: a case study on two desmopressin nasal spray preparations, Eur J Clin Pharmacol, 59, pp.: 631-636, 2003

[8] Maifeller D. et al., A high-performance silicon micropump for an implantable drug delivery system, Proc. of the 12th IEEE MEMS 1999 Technical Digest, Orlando, FL, USA, pp 541-546, 1999. 